\title{
Een forensisch psychiatrische setting vanuit psychoanalytisch perspectief *
}

\author{
K. van Tuinen**
}

Van de wel meer dan duizend gedetineerden in de gevangenis waar ik eerder gewerkt heb en mijn ervaring heb opgedaan, zijn er een aantal die ik nooit zal vergeten.

$\mathrm{X}$ had een reputatie opgebouwd van een gevaarlijke crimineel, een recidivist die het grootste deel van zijn leven in de gevangenis had doorgebracht. Zelfs daar bleek hij moeilijk te handhaven en tenslotte was hij in de zwaarst beveiligde setting beland. Buiten de gevangenis bestond zijn leven uit het plegen van ernstige geweldsdelicten zoals gewapende overvallen en gijzelingen.

Tegen de tijd dat zijn invrijheidstelling naderde kreeg ik intensief contact met hem. Naast de overweldigende dreiging en de haat die hij uitstraalde kon je met rust toch tot hem doordringen en bij zijn angstige en afhankelijke kern komen, bij zijn behoefte aan geborgenheid die hij nooit gevonden had en bij zijn stil verlangen naar een gewoon leven, waarvan hij niet wist hoe dat er uitzag.

Bij hem groeide voelbaar mijn besef over het hulpeloze en hopeloze kind in hem, dat al heel vroeg in zijn ontwikkeling stuurloos was blijven steken, maar waarvan alleen het lichaam doorgegroeid was.

De wraakzucht over wat hem tekort gedaan was en het de maatschappij betaald willen zetten leek hem te drijven tot zijn agressieve daden.

Psychotisch was hij niet, behandeling had hij nooit gehad en wilde hij ook niet vanuit zijn angst voor nabijheid en intimiteit, het woord patiënt kon hij niet horen. Terugkeer in de vrijheid was er voor hem niet bij. Hij bleef gevangen in zijn eigen gevangenis van waaruit ontsnappen onmogelijk was.

* Deze bijdrage is een verkorte versie van de inleiding gehouden op het Europees Psychoanalytisch Congres, Berlijn, 27 maart 1999. De volledige tekst is opgenomen in 'Om ernstige zaken, opstellen ter gelegenheid van het vijftig jarig bestaan van het Pieter Baancentrum', Deventer 1999.

** Hoofd forensisch-psychiarische kliniek van het APZ Drenthe. 
Zo voert deze patiënt ons de forensische psychiatrie binnen, dat een breed vakgebied is met veel disciplines, dilemma's, paradoxen en met complexe keuzen en moeilijke beslissingen, dat tegelijkertijd een grote aantrekkingskracht kan hebben op behandelaars vanwege de uitdaging die er ligt in het ontwikkelen van nieuwe behandelmethodieken en settingen voor deze categorie patiënten. De forensische psychiatrie zelf kan bij dit alles niet los gezien worden van zijn juridisch-normatieve en ethische context en van de maatschappelijke discussie over gevaar en veiligheid (1).

Precies 5 jaar geleden werd een nieuwe forensisch psychiatrische kliniek en polikliniek als onderdeel van het Algemeen Psychiatrisch Ziekenhuis te Assen in Nederland in gebruik genomen. In het voorbereidingstraject was het onontkoombaar eerst stil te staan bij de essentiële vraag wat de functie van deze kliniek diende te zijn, die gepositioneerd werd op de grens van justitie en volksgezondheid.

Daarvan afgeleid kwamen vele andere kwesties aan de orde zoals voor welke patiënten de kliniek bestemd was, kon de kliniek patiënten weigeren, waren er naast de algemene ook specifieke behandeldoelen, voor welk behandelmodel moest gekozen worden of konden meerdere modellen naast elkaar bestaan, welk type therapeutisch milieu moest als overkoepelend kader ontwikkeld worden; vervolgens de meer praktische als de vormgeving van het gebouw, de stafopbouw, het deskundigheidsniveau van de medewerkers, het juridisch kader en de rechtspositie van de patiënten, de interne regelgeving en last but not least de veiligheid als een conditio sine qua non.

Al deze aspecten dienden bovendien een samenhangend, consistent en organiseerbaar geheel te vormen (2).

Dat de psychoanalyse een belangrijke bijdrage zou dienen te leveren stond niet ter discussie, maar dat zij het metapsychologisch kader zou zijn en de behandelsetting zou domineren sprak niet vanzelf.

Een startende kliniek moet zoals een kind zich ontwikkelt, kunnen groeien, van zijn ervaringen leren en vooral niet in een doctrinair keurslijf gestopt worden.

Zo is in de afgelopen jaren wat eerst een idee was, uitgekristalliseerd, in de praktijk beproefd en waar nodig bijgesteld.

\section{Uitgangspunten voor onze behandelsetting}

Evenmin als DE forensisch psychiatrische patiënt bestaat, is er EEN behandelsetting voor deze patiënten. 
Enerzijds moeten de patiënten gedifferentieerd worden naar:

sexe, leeftijd, intelligentie, psychiatrische stoornis, persoonlijkheidsstructuur, delikt en delinquente loopbaan, risico van delictrecidive, actuele gevaarlijkheid en taxatie van gevaarlijkheid op langere termijn, sociaal netwerk, juridische maatregel, de mate van noodzakelijke beveiliging c.q. vrijheidsbeperking en behandelbaarheid, waaronder ook een taxatie van eventuele chroniciteit.

Anderzijds moet de behandelsetting de behandeling ondersteunen en toegesneden worden op de doelgroepen van de patiënten. De behandelsetting is het overkoepelend kader van de behandeling en omvat een geïntegreerd en op elkaar afgestemd geheel van de behandelinhoud zoals behandelconcepten, behandeldoelen, behandelmiddelen, behandelprogramma's en therapeutisch milieu en de behandelorganisatie als het gebouw, stafopbouw, interne regelgeving,etc.

De behandelsetting kan niet alleen klinisch maar ook ambulant of een combinatie van beide kan zijn.

Een doorsnee afdeling van een psychiatrisch ziekenhuis of ambulatorium, justitiële behandelkliniek of penitentiaire inrichting voldoet niet zo maar aan de specifieke eisen die aan effectieve behandeling van forensische patiënten gesteld moeten worden.

Uit een Canadees criminologisch onderzoek (9) naar de effectiviteit van 44 rehabilitatieprogramma's voor delinquenten komt naar voren dat uit de veelheid van variabelen er slechts zes karakteristieke elementen werkbaar lijken te zijn :

- een gezond conceptueel model gericht op recidive preventie, i.c. cognitive-behavioral theoretical model werkt beter dan een uitsluitend analytisch model;

- een rijk geschakeerd en vanwege de complexe problematiek een multimethodische behandelings- en interventieprogramma;

- dat gericht is op verandering van psychogene en criminogene behoeftes, die recidive bevorderen zoals verandering van antisociale gevoelens en attitudes, identificatie met sociale rollen, ontvangen van sociale waardering, verbetering van maatschappelijke omstandigheden en individuele risk assesment;

- het responsivity principle, d.w.z. de mate waarin een succesvol programma aansluit bij de leerstijl van de deelnemers, i.c. gedragstherapeutische en social learning technieken;

- roleplaying/modeling, het voorbeeld gedrag van de staf ter verbetering van empathie-ontwikkeling, et oplossen van problemen met medemensen en sociale vaardigheden; 
- social cognitive skills training gericht op het denken van de delinquent, met name hem leren hoe hij denkt; daarna komt verandering van wat hij denkt door middel van psychotherapie aan de orde.

Vanuit een oriëntatie op dergelijke principes en ervaringen van anderen (10) hebben wij een kliniek voor 54 forensisch psychiatrisch patiënten (mannen en vrouwen) ontwikkeld met het volgende karakter :

- de patiënten moeten minstens enige commitment hebben met hun behandeling en de veiligheid;

- wanneer patiënten met dwang zijn opgenomen en in een ernstige psychotische toestand verkeren, moet gestreefd worden naar een zo spoedig mogelijke commitment;

- een juridische maatregel moet werken als drang om tot dat commitment ter komen;

- de patiënt moet steeds blijven kunnen kiezen voor behandeling of voor beëindiging van behandeling;

- veiligheid is een basisvoorwaarde voor de behandeling;

- basisregels als verbod op geweld, drank, drugs, onderlinge sex en handel gelden voor patiënten en personeel;

- de behandelfilosofie berust op een drietal richtinggevende principes: het recht op respect, afspraak is afspraak en verantwoordelijkheid naar draagkracht;

- het algemene behandeldoel is het verminderen of opheffen van psychiatrische stoornissen en het trainen van praktische, cognitieve, sociale en interactionele vaardigheden;

- specifiek doel is preventie van delictrecidive bij de behandeling van agressieve en sexueel-agressieve stoornissen;

- het overkoepelend kader is supportieve milieutherapie, dat wil zeggen ikondersteunend en anti-regressief, gericht op symptoom-vermindering en op verbetering van intacte functies en vaardigheden en met de nadruk op het hier en nu;

- de behandeling is groepsgericht waar mogelijk en individueel waar nodig;

- iedere patiënt beschikt over een eigen behandelplan waarmee hij instemt;

- er is in de startfase van de kliniek geen primaat aan een bepaald theoretisch referentiekader toegekend;

- de kliniek kent een interne differentiatie, toegesneden naar zeven doelgroepen:

1. diagnostiek, acute psychiatrie en crisisinterventie

2. activering van chronisch psychotische patiënten

3. ernstige borderline persoonlijkheidsstoornissen 
4. ernstige narcistische stoornissen

5. sexuele stoornissen

6. rehabilitatie

7. resocialisatie

- daarnaast zijn er in de regio drie forensische poliklinieken in ontwikkeling.

Hoe laat nu deze behandelingsetting zich vanuit de zes metapsychologische gezichtspunten en de drie latere pijlers van de psychoanalytische theorie, de ik-psychologie, de zelf-psychologie en de object-relatietheorie beschrijven?

De kliniek is als het ware een levensschool, waar ik-zwakke patiënten komen om te groeien in hun executieve en synthetische functies (11), in hun supergo ontwikkeling en in het intra- en interpersoonlijk leren, d.w.z. het oplossen van crises en het aanleren van verschillende sociale rollen (12).

Milieutherapie in de kliniek, c.q. sociotherapie (13), is de methodische hantering van het leefklimaat, geënt op een stabiele samenhangende sociale organisatie en waarbij stad, gebouw, organisatie en communicatie geheel in dienst van de behandeling staan. Hieronder vallen niet alleen de sfeer en het klimaat in huis, het gestruktureerde dagprogramma, de verschillende therapieën, maar ook het dagelijks leven van de patiënten: wonen, werken, vrije tijd met gewone sociale omgang. Patiënten hebben een eigen kamer met een eigen sleutel ter wille van hun privacy, leren koken, doen corvee, doen handvaardigheid op in de arbeidstherapie, sporten en zwemmen, volgen onderwijs; daarnaast is er een recreatiecommissie en een patiënten-vertegenwoordiging.

Supportieve milieutherapie (14), die gekenmerkt wordt als ik-ondersteunend, anti-regressief, gericht op symptoomvermindering en verbetering van de intacte functies met de nadruk op het hier en nu en die moet worden onderscheiden van reconstructieve en sociaal therapeutische milieutherapie, is bij uitstek geïndiceerd voor onze patiëntenpopulatie met hun vroege stoornissen.

De staf, die de realiteit vertegenwoordigt en een voorbeeldfunctie vervult, dient als een ik-prothese en neemt tijdelijk bepaalde ik-functies van de patiënten over. De patiënt behoudt zolang mogelijk en zoveel mogelijk zijn eigen autonomie. Hij wordt geacht verantwoordelijk te zijn voor zijn leven en die verantwoordelijkheid ook te dragen. Daarin past ook het onderschrijven van de huisregels en het zich houden aan de basisregels, die de veiligheid dienen en een criminele subcultuur in de kliniek tegen moeten gaan.

Het individuele behandelplan is de formele crux van de behandeling en is sterk probleemgericht. Patiënt en staf komen schriftelijk overeen waaraan 
voor de komende tijd gewerkt zal worden, wat de specifieke behandeldoelen zijn, welke therapieën gevolgd zullen worden, wat hij concreet wil afleren en aanleren, welke medicatie hij gebruikt en hoe en wanneer de patiënt de staf zal vragen hem te helpen.

In een latere fase komt ook de toekomst aan de orde met de maatschappelijke reïntegratie en het leren accepteren van eventuele handicaps.

We gebruiken in de kliniek opzettelijk het woord patiënt, opdat hij zich niet langer identificeert met zijn delinquent zijn maar zichzelf mag gaan beleven als iemand die het recht heeft op verbetering van zijn situatie.

De behandeling is gericht op activering van de patiënten om zijn oude paden te verlaten en nieuwe stappen te gaan zetten. Concreet gaat het hier om een verbeterde zelfcontrole ten aanzien van geweld, sexuele agressie, alcohol- en drugsgebruik. Zonder toenemende angst, opleving van oude conflicten en agressieve acting-out gaat dit in de regel niet. Bijna altijd geraken patiënten op een punt waarop ze willen afhaken. Het overwinnen van een dergelijke crisis is voor hen een echte ik-versterking. In principe kan een patiënt, die zijn behandeling stopt, later terug komen voor een nieuwe intake en de draad van zijn behandeling weer opnemen.

De emotionele context van de behandeling moet de kliniek waarmaken in het scheppen van een klimaat, waarbij de patiënt zich welkom kan voelen, menselijke betrokkenheid kan ervaren van zijn behandelaars, hoop kan putten uit het feit dat er een kliniek is die met hem aan zijn problematisch leven wil werken.

Hier gaat het er om of de patiënten in staat zijn hun zelf te ontdekken en zelfgevoel te ontwikkelen en uiteindelijk een realistisch gevoel van eigenwaarde te ervaren.

Bijna altijd staan de patiënten bij binnenkomst met hun rug tegen de muur en hebben geen ander alternatief meer dan de ambivalente stap naar behandeling te maken en zich op te laten nemen. Het moeten veranderen is zeer bedreigend voor hen. De uitkomst ervan is voor hen niet te overzien.

In de holding environment van de kliniek moet het kind in de patiënt the good enough mother kunnen ontwaren (15). De patiënten moeten dit kunnen voelen in containende attitudes als acceptatie, geborgenheid, veiligheid, voorspelbaarheid, overzichtelijkheid, beschikbaar zijn, tijd hebben en zonodig maken, aan willen horen, verwoorden van niet uit te spreken gevoelens. Met name de non verbale therapieën als creatieve, muziek en psychomotore therapie spelen een belangrijke, vaak ook confronterende, rol bij het los maken van innerlijke potenties.

Bij de psychomotore therapie werken we bijvoorbeeld met grote spiegels en met video-opnames, die een coherente lichaamsbeleving versterken en een 
realistische acceptatie van het eigen lijf bevorderen. Patiënten leren zo zichzelf zien, sommigen durven dat hier voor het eerst in hun leven.

Niet alleen bij individuele en groepspsychotherapieën maar met name ook in de dagelijkse afdelingsbesprekingen, tijdens het gezamenlijk koffiedrinken en eten, worden de patiënten gestimuleerd zich te uiten en te verwoorden wat zij voelen en willen. Steeds worden zij serieus genomen.

Deze containing en spiegeling vraagt van het personeel een grote mate van professionaliteit, innerlijke stabiliteit, kunnen omgaan met nabijheid en afstand, zich kunnen inleven in de psychologische kinderwereld van de patiënten en bestand te zijn tegen hun onvermijdelijke minachting en diskwalificaties.

Periodieke reflectie in de behandelteams op de eigen gevoelswereld en op tegenoverdrachtmanifestaties, met name bij idealiserende overdracht, projectieve identificatie en splitsingfenomenen, en continue herijking van de kliniekstructuur zijn noodzakelijke voorwaarden hierbij.

Voortdurend moet men alert zijn voor het ontstaan van parallel processen bij stafleden en desintegratietendensen in de behandelteams. Werkbegeleiding, supervisie en soms ook een eigen psychotherapie zijn hierbij onmisbare instrumenten om de eigen belevingswereld te kunnen scheiden van die van de patiënten.

Een specifiek probleem in de kliniek is het plegen van geweld en agressie door patiënten. Het stellen van een verbodsregel voorkomt dit natuurlijk niet. De staf, die hierop extra getraind is, moet in voorkomende gevallen zo snel mogelijk de patiënt fysiek zien te bedwingen en de patiënt een veilige situatie voor zich zelf en anderen weer laten herstellen. In een forensisch psychiatrische kliniek is het angstniveau onder de staf per definitie hoog, waar de patiënten immers zonder uitzondering bewezen hebben voor hun opname tot ernstige delicten in staat te zijn geweest. In plaats van deze gevoelens te verdringen of anderszins af te weren moet de staf zich vrij voelen de angst openlijk te bespreken en te delen met elkaar en dit ook op indicatie zonodig met de patiënt die de angst oproept.

Werkelijk onmisbaar in de behandeling is een goed zicht op de archaïsche binnenwereld van de patiënten. Deze intrapsychische wereld met de self- en object-representaties is slechts te kennen door een continue interactie van de staf met de patiënten. Hun uitingen en hun gedragingen met de specifieke vroege afweerpatronen als loochening, splitsing en projectieve identificatie geven zicht hoe zij zich zelf in verhouding tot anderen beleven. Zonder uitzondering is hun ontwikkelingsstoornis voelbaar in het contact en goed 
luisteren naar de eigen tegenoverdrachtgevoelens brengt je in de regel naar de primitieve kern van hun complexe belevingswereld.

Wanhopige kwetsbaarheid en leegte, angstig gedreven agressie, door wraakzucht ingegeven sadisme en vernietigingszucht, onmachtige en afhankelijke idealisering leveren de voedingsbodem voor hun delicten, waarin zij de vroegere traumatisering herbeleven, willen vereffenen maar tevergeefs trachten op te lossen.

Het is deze scheefgegroeide representational world met zijn vele als slecht ervaren introjecten, die wij moeten zien te bereiken, omdat deze zo richtinggevend is voor hun gedrag en hun delicten. Wanneer zij eenmaal een diepergaande relatie aan hebben durven te gaan met de staf, die oprecht, empatisch, ondersteunend, maar ook recht-toe-recht-aan en grenzend stellend is en zich als een nieuw identificatie object van vervangvader en vervangmoeder aanbiedt, kan hun emotionele binnenwereld positiever geladen worden.

De innerlijke strijd tussen enerzijds ervan overtuigt te zijn dat de omgeving je alleen maar vijandig gezind is en je wil vernietigen en anderzijds de toenemende ervaringen dat er om je gegeven wordt, is niet snel beslecht.

Het voeren van dit gevecht in en om de patiënt is de eigenlijke inzet van de behandeling, die moet leiden tot verminderde splitsing en projectieve identificatie, dus tot een minder paranoïde levensinstelling en het beter kunnen verdragen van innerlijke ambivalenties en frustraties.

De behandeling richt zich op verandering van de oude geïnternaliseerde selfobject wereld en schept daarmee de voorwaarden voor het op gang brengen van verdere ik en super-ego ontwikkeling en het veranderen van de angst, agressie en afweer huishouding.

Deze structurele verandering in de persoonlijkheidsopbouw kan uiteindelijk het gevaar van delictrecidive zodanig doen verminderen dat geleidelijke reïntegratie van de patiënt in de samenleving weer verantwoord en mogelijk is.

Alles wat hier tot nu toe gezegd is over wat ik zie als het overkoepelend psychoanalytisch denkkader in de kliniek vindt een genuanceerde toepassing in de dagelijkse behandelpraktijk zowel ten aanzien van de individuele patiënt als ten aanzien van de onderscheiden patiënten categorieën op hun verschillende afdelingen.

Daar waar bij een patiënt een psychose voor op staat, is de behandeling meer medisch-psychiatrisch gericht en zeker in geval van chroniciteit ligt de nadruk meer op care dan op cure, op rehabilitatieprogramma's en op het doen accepteren van het blijvend gehandicapt zijn. Wanneer de veiligheid het toelaat kunnen deze patiënten worden overgeplaatst naar algemene 
psychiatrische ziekenhuizen of in vormen van beschut en begeleid wonen in de maatschappij worden opgenomen. Een klein aantal moet uiteindelijk vanwege het grote delictrecidive-risico blijvend geasyleerd worden.

Bij patiënten evenwel met ernstige narcistische en borderline persoonlijkheidstoornissen en waarbij de psychose meer op de achtergrond staat, kan ten aanzien van de voortdurende dynamiek die zij veroorzaken op hun afdeling, de overdrachtsmanifestaties en het profiel van hun gestagneerde ontwikkeling met veel meer vrucht van het psychoanalytisch referentiekader gebruik worden gemaakt.

Psychodynamische interventies dienen vooral gericht te zijn op het hier en nu van de interacties, op verheldering van de overdracht en de afweerpatronen, op ondersteuning van het ik en het ontwikkelen van inzicht in de gevolgen van het actuele doen en laten. Genetische duidingen, toestaan van regressie, intellectualisaties en rationalisaties moeten door de staf beslist achterwege gelaten worden. Wat zich afspeelt in de realiteit staat centraal in de omgang van deze patiënten met de staf, die daarbij in zijn steunende en begrenzende functie het zelf van de patiënten voedt, het ik versterkt, en de normontwikkeling op gang brengt.

Behandeling in een forensisch psychiatrische kliniek kan niet om het feit heen dat zijn patiënten ook delinquenten zijn die ernstige strafbare feiten begaan hebben ten aanzien van vaak onschuldige slachtoffers.

In dit verband werken we veel met cognitieve gedragstherapie, waarin de patiënten leren verantwoordelijkheid te nemen voor hun eigen daderschap en de gevolgen daarvan, hoe hun delictscenario stapsgewijs is opgebouwd, wanneer zij in de gevarenzone van nieuwe delicten komen en hoe zij in dat geval hulp moeten inroepen.

Het zich kunnen identificeren met slachtoffers en het ontwikkelen van empathie is een verder verwijdert doel van de behandeling. Dit is echter voor het merendeel van de patiënten niet of slechts ten dele haalbaar.

Met name geldt dit voor patiënten met een ernstige antisociale persoonlijkheidsstoornis en waarbij de gewetensfunctie lacunair dan wel afwezig lijkt te zijn.

Hoewel de psychoanalyse sinds Freud fundamentele theoretische bijdragen geleverd heeft aan het begrijpen van het karakter van de misdadiger, is de praktische toepassing in onze klinische setting beperkt.

Klassieke reconstructieve psychoanalyse is, gelet op onze patiëntenpopulatie niet geëigend.

Wel vindt op indicatie individuele en groepssupportieve, soms ook in exploratieve richting gaande, psychodynamische psychotherapie plaats naast 
relatie- en gezinstherapie, directieve en de reeds genoemde cognitieve gedragstherapie.

Uiteindelijk gaat het erom een mede door de psychoanalyse gevoed coherent multitheoretisch en multimethodisch frame voor de gehele kliniek te ontwikkelen en verder te verfijnen, waarbij voor de individuele patiënt die mix aan behandelstrategieën wordt gekozen die, toegesneden op zijn pathologie, zijn verbetering en genezing dienen.

Een goede leidraad hierbij is het model van Rockland (16) dat steunt op het werk van Winnicot, Bion, Kernberg, Masterson, Adler, Appelbaum en Munich, Gunderson, Ogden, Stern, Levine en Wilson.

Rockland onderscheidt een zevental supportieve elementen met betrekking tot klinische behandeling van borderline patiënten, te weten:

retreat, uit de destabiliserende omgeving vandaan

- framing, de afdeling zekert desintegratie en acting-out;

- holding, de ik-ondersteunende functie;

- detoxification, destructieve scenario's doorbreken;

- identification, het aanbieden van identificatiemodellen;

- supportieve aspecten van specifieke therapieën als farmaco-, gezinscognitieve-gedrags-, psychodynamische therapie en rehabilitatie programma's.

Naast deze psychodynamische bouwstenen zullen wij ten aanzien van de meer concrete vormgeving moeten putten uit wetenschappelijke studies, die schaars, methodologisch zwak en qua resultaten vaak dubieus zijn (17).

Vanuit internationaal onderzoek (18) naar effectiviteit van behandelprogramma's blijkt echter wel het volgende:

de nulhypothese dat niets werkt is niet houdbaar.

- intensieve programma's moeten worden besteed aan patiënten met ernstige recidive-risico's en vooral niet aan de lichtere gevallen;

het behandelarsenaal moet gericht zijn op antisociale attitudes, het conformeren aan de eigen leeftijdsgroepen (peer associations), afhankelijkheid van drugs, identificatie met antisociale modellen, sociale vaardigheden en zelfcontrole, en zelfmanagement;

- delinquenten zijn het meest vatbaar voor gedragstherapeutische, social learning programma's van therapeuten met een stevige en tegelijk eer-lijke benadering, gericht op modeling en beloning van anticriminele gedachten, gevoelens en daden. 
Verdere research is hier perse noodzakelijk, met name geldt dat de vragen in hoeverre succesvolle programma's voor jeugdigen ook werkzaam zijn voor volwassenen en of psychopaten überhaupt behandelbaar zijn. Dit laatste stoelt op een speculatieve hypothese dat psychopathie geen stoornis is, maar in genetische zin een vorm van adaptatie, die resistent is voor de huidige therapie.

Dit gegeven is met name voor de toekomst van de TBS van uitzonderlijk belang, omdat thans niet primair de behandelbaarheid van deze categorie patiënten als wel de veiligheid van de samenleving centraal staat bij het opleggen van deze maatregel.

Tenslotte, forensische psychiatrie houdt zich begrijperlijkerwijze meer bezig met agressie en dan vooral met de destructieve agressie dan met de libido.

Wij behandelen geen agressie an sich, maar patiënten met ernstige agressieve en seksueel agressieve stoornissen in het licht van hun ontwikkelingsgeschiedenis en hun psychodynamiek (19).

Interessant is de studie van Sidney Furst (20), die weliswaar voortbouwt op de oude analytische agressie theorie, maar behandelaars een nieuwe impuls geeft om met hun patiënten te werken aan constructievere vormen van agressie en een betere inbedding ervan in de persoonlijkheid.

\section{Literatuurlijst}

1. Mooy, A., Psychiatrie en de menselijke maat. Amsterdam, Boom, 1998.

2. Behandelnota FPK. Assen, 1997.

3. De forensische psychiatrie en haar raakvlakken. Nota NRV, 1991.

4. Millon, Th., Disorders of personality: DSM-IV and beyond. New York, John Wiley and Sons, 1996.

5. Bulten, B.H., Gevangen tussen straf en zorg. Wolters-Kluwer Ned., 1981 .

6. Akhtar, S., Broken structures. Northvale, New Jersey, Jason Aronson, 1992.

7. Freud, S., Die kulturelle sexual Moral und die moderne Nervositat. 1908.

8. Kernberg, O.F., Aggression in personality disorders and perversions. New Haven, Yale University Press, 1992.

9. Antonowicz, D.H., Ross, R.R., Essential components of successful rehabilation programs for offenders. International Journal of Offender Therapy and Comparative Criminology, 38(2), 1994. 
10. - Janssen, P.L., Psychoanalytische therapie in der klinik. Stuttgart, Klett Cotta, 1987.

- Kernberg, O.F., Object relations theory and clinical psychoanalysis. New York, Jason Aronson, 1976.

- Marle, van H.J.C., Een gesloten systeem. Arnhem, Gouda Quint, 1995.

- Silver, D. and Rosenbluth, M., Inpatiënt treatment of borderline personality disorder. Borderline personality disorder, ed. Joel Paris. Washington, DC, American Psychiatric Press, 1993.

- Wallace, E.R., Dynamic psychiatry in theory and practice. Philadelphia, Lea and Febiger, 1983.

11. Hartmann, H., Essays on ego psychology. London, Hogarth Press, 1964.

12. Cumming, J. and Cumming, E., Ego and milieu. New York, Atherton, 1962.

13. Jongerius, P.J., Rylant, R.F.A., Milieu als methode. Meppel, Boom, 1989.

14. Janzing, C., Lansen, J., Milieutherapie. Assen, Van Gorcum, 1993.

15. Winnicot, D.W., The maturational processes and the facilitating environment. New York, International University Press, 1965.

16. Rockland, L.H., Supportive therapy for borderline patiënts. New York, The Guilford Press, 1992.

17. Monahan, J., Steadman H.J., Violence and mental disorder, developments in risk assessment. Chicago, The University of Chicago Press, 1994.

18. - Andrews, D.A. et al., Does correctional treatment work? Criminology, 28, 369-404, 1990.

- Lipsey, M.W. \& Wilson, D.B., The efficacy of psychological, educational and behavioral treatment. American Psychologist, 48, 11811209, 1993.

19. - Aggression, contemporary controversies. Psychoanalytic Inquiry volume 18, number 1, 1998.

- Freud, A., Comments on aggression. Int.J.Psycho-Anal. (1972) 53, 163.

- Parens, H. The development of aggression in early childhood. Northvale, New Jersey, Jason Aronson, 1994

- Furst, S.S. A psychoanalytic study of aggression. The Psycho-analytic Study of the Child, vol 53/1998. 